\title{
4. Communities of practice and the everyday making of EU foreign and security policy
}

Niklas Bremberg and August Danielson

\section{THE LIMITS OF THEORIES OF SOCIALIZATION AND PRACTICE}

We argue that the 'classic' conceptions of socialization theory and practice theory are insufficient for understanding how practices are diffused as well as how contestation is managed in the field of European Union (EU) foreign and security policy. The question of how contestation affects EU policy-making has gained increased scholarly attention in recent years (see Chapter 1). Nevertheless, EU foreign and security policy showcases a high degree of continuity and, in some fields, has even expanded. Therefore, this chapter generates an analytical framework that explores questions related to learning and contestation in the everyday formation of EU foreign and security policy, beyond the sometimes oversimplified assumptions in socialization theory and 'Bourdieuan' practice theory (these assumptions are presented in detail below). Such questions include how contestations by member states and their representatives affect the general compliance to the norms, rules and procedures in the EU foreign and security policy system, as well as how shared practical understandings of EU foreign and security policy change as a result of contestations in, for example, the Political and Security Committee (PSC) and Council Working Groups (CWGs). In addition, it is necessary to examine how norms, rules and procedures of EU foreign and security policy are learned and contested in the everyday work of EU officials in the European External Action Service (EEAS) and EU delegations in third countries. Although we primarily emphasize the effects of macro-level contestation (between member states) on micro-level interaction (between individual practitioners), contestation on the meso level (between groups and/or institutions) also shapes the practices of EU foreign and security policy. The effects of these contestations are examined in the empirical chapters of this volume (Chapters 5-9). 
We develop our analytical framework by centring on the concept of communities of practice. Our definition of such communities is based on Etienne Wenger and Emanuel Adler's definition: '[communities of practice are] like-minded groups of practitioners who are informally as well as contextually bound by a shared interest in learning and applying a common practice' (Adler, 2008, p. 196; see also Wenger, 1998). In this sense, the concept of communities of practice assumes both socialization theory and practice approaches, while balancing some of the inadequacies of both theoretical approaches: primarily, the notion that the socialization of a group's norms does not necessarily lead to uniformity within the group, as well as the possibility that practitioners can and do reflect on prevailing practices to improve or contest these practices (Adler, 2019, pp. 19-20).

Unlike other researchers, we conclude that communities of practice in EU foreign and security policy do not include formalized groups such as the PSC, EU delegations and EEAS units, as we found that communities of practice cannot be reduced to formal groups and institutions within the EU. That is, institutional affiliations per se do not explain how common EU actions are shaped, how council conclusions are negotiated, how decisions are implemented by the EEAS, and how lessons from CSDP operations and missions are learned (see Bremberg, 2016b; Bremberg et al., 2019). Building on insights gained from practice approaches and socialization theory, we argue that we are better equipped to analyse these essential dynamics by focusing on practical understandings and ways of doing things, forged by everyday interactions in communities of practice clustered around (but not completely overlapping with) the social venues that formal groups and institutions in the EU provide (see Adler-Nissen, 2014a).

Importantly, we do not assume that members of a particular community of practice in the field of EU foreign and security policy always agree with one another, and that consensus-seeking is what ultimately holds such communities together. In this sense, we do not share the assumption held by many socialization scholars in international relations (IR) that social interaction always has homogenizing constitutive effects. In other words, we do not assume that all social interaction eventually results in the participating actors adopting similar identities and preferences (Wendt, 1999; Johnston, 2008). In fact, the processual, temporal and conflictual character of social practices is key to understanding how practices make certain policy outcomes more likely, and under what conditions the social boundaries of communities of practice are reshaped (Swidler, 2001; Nicolini, 2013). The framework we developed also helps to specify what contestations and learnings in communities of practice result in intensified socialization or changing norms, rules and procedures on the basis of new shared practical understandings. 
Our framework challenges three main theoretical claims. First, 'like-minded' does not necessarily mean 'same-minded' in communities of practice. Michael Barnett has argued that in addition to being a site for defining and organizing collective action, 'communities of practice also become a place where battles are waged over resources, status and identity' (Barnett, 2018, p. 320). Therefore, we contend that practices allow for more reflexivity than what has previously been argued by some practice theorists, most notably Vincent Pouliot (2008). Specifically, we argue that although reflexivity about a group's practices may be practically non-existent at certain times (for example, when a new member enters a working group and chooses to unreflectively mimic the group's practices), reflexivity about the appropriateness and utility of the group's practices may also increase as the novice becomes more accustomed to these practices. Such conscious reflection may also lead to different outcomes, such as sustained contestation, the habituation of the practice, or the development of new practices (Adler, 2019, pp. 219-233).

Second, the possibility that practices can be reflected upon also means that practices should primarily be understood from an internalist perspective (that is, from the perspective of the practitioners themselves), as we otherwise may risk making incorrect judgements about the meaning of certain context-bound conditions (Lechner and Frost, 2018). This approach does not mean that we only use the language of the practitioners themselves to explain the practices in a given setting, but rather that we should strive to understand what a group's practices are by using their descriptions of their practices. For this reason, we primarily analyse interviews with practitioners in the groups and institutions of EU foreign and security policy.

Third, although we do not assume that socialization inherently leads to homogenizing constitutive effects, previously theorized mechanisms of socialization - for example, mimicking, social influence and normative suasion (Johnston, 2008) - are useful conceptual tools for understanding how and when practices become objects of conscious reflection, as well as how that reflexivity can vary over time. In this sense, using socialization mechanisms to understand how practices are learned can help us to gain a nuanced understanding of practical learning, while also taking into account that diplomats and officials in EU foreign and security policy are seldom novices in their professions; even though they might at times be new to particular groups and institutions in the EU, their experience shapes the dynamics of the communities of practice that we seek to study. 


\section{SOCIALIZATION THEORY AND PRACTICE APPROACHES IN EU FOREIGN AND SECURITY POLICY}

As mentioned above, two theoretical perspectives which share the assumption that groups of actors can create standards of appropriateness and competence, but differ in terms of how they explain the actions of individual agents, are socialization theory and practice approaches. While socialization theory primarily aims to explain the process through which institutional environments affect actors' 'cognition, attitudes, and identity' (Lewis, 2005, p. 938), and consequently inculcates them into the norms and rules of a given community (Checkel, 2005), practice approaches tend to emphasize a distinct social ontology that focuses on materially embodied interwoven practices centrally organized around shared practical understandings (Schatzki et al., 2001). The latter suggests that the internalization of norms is inconsequential for the understanding of the 'social theatre of world politics'. As long as people act in line with shared meanings (understood as established practices), their motives to do so, according to most practice theorists, are quite irrelevant (Pouliot, 2016, p. 18). In the following, we describe both perspectives in greater detail.

\section{Socialization Theory}

Socialization is the process of individuals developing a sense of belonging with a group and adapting their behaviour accordingly (Beyers, 2010, p. 909). Socialization theory in IR views state actors' identities and preferences as redefinable through persuasion (Checkel, 2005, p. 812). Underlying this process of norm conformity is the logic of 'communicative rationality', which Habermasian social theory defines as the outcome of successful communication (Checkel, 2005, pp. 812-813). Therefore, socialization is a dual process of persuasion and norm adoption. For actors to change their beliefs, they must first be exposed to the arguments that explain why the norm or rule in question is normatively or instrumentally superior.

The outcome of socialization is often designated as internalization or 'the sustained compliance of an agent to act in accordance with what is socially accepted in a given setting or community' (Checkel, 2005, p. 804). Internalization is understood as both the end result of socialization and the conscious goal of the group members to sustain the socialization process. By accepting the norms and rules of a community, a state agent no longer acts according to the logic of expected consequences, but rather on the basis of what action is seen as the most appropriate in a certain social setting, for example, in a CWG in the EU. However, the conceptual distinction between 
a rational agent and a socialized agent is not clear cut. For example, it is not always those who are completely convinced of a norm that aim to persuade others of its legitimacy. Often people can also socialize and persuade others to directly maximize their preferences because they are convinced that their rule-conforming behaviour will somehow benefit them in the future. Essentially, the process of socialization should partly be understood as an effort of conscious persuasion, even if the attempt is motivated by different logics of action (for example, instrumentality, conformity or legitimacy). Jeffrey Checkel defines these socialization mechanisms as strategic calculation, role-playing and normative suasion, representing three modes of rationality: instrumental, bounded and communicative (Checkel, 2005, p. 805). Although strategic calculation assumes that actors follow the rules of a group because actors are instrumentally rational, actors socialized through role-playing do so because they perceive rule-following to be 'socially easier' than instrumental calculation (Checkel, 2005, p. 811). ${ }^{1}$ Finally, the mechanism of normative suasion assumes that actors increasingly follow the rules of a group because they have been persuaded that they should modify or completely change their core beliefs and interests. In essence, the process of socialization should also be understood as the socialized agent's incremental shift from instrumentality (cost-benefit analysis) to communication (successful persuasion) as their main basis of action (Checkel, 2005, p. 805).

A closely related way of theorizing socialization is offered by Alastair Iain Johnston (2008). Focusing on China's participation in international institutions between 1980 and 2000, Johnston suggests that socialization primarily works through three mechanisms: mimicking, social influence and persuasion. Johnston argues that novices in international institutions are usually socialized through mimicking: a new member to a group imitates the actions of the other members of the group not because the actions are rational, but because imitation is the safest course of action in an uncertain environment. After one has learned the rules of the game and the potential costs of acting contrary to the group's norms, an actor may either defect or continue to act in line with the group's norms, for reasons of either social influence or persuasion. Although the mechanism of social influence primarily works through social rewards and punishments (that is, actors want to feel that they belong in a group, and want to avoid being shunned or shamed), the mechanism of persuasion works similarly to normative suasion, as actors actively and consciously assess the milieu of norms, values and causal understandings, which over time leads to the redefinition of their preferences and beliefs.

1 In this sense, the socialization mechanism of role-playing is very closely related to Theodore Hopf's notion of a logic of habit (Hopf, 2010, 2018). 
Previous research on socialization in IR and European studies often departed from the assumption that Europe with 'its dense network of regional organizations ... easily qualifies as the thickest institutional environment beyond the nation-state anywhere on the globe and is thus a most likely case for socialization dynamics' (Zürn and Checkel, 2005, p. 1065). For this reason, much of socialization theory is based on empirical observations of socialization processes among national diplomats and EU officials. For example, Jeffrey Lewis has applied socialization theory to study everyday decision-making in the Committee of Permanent Representatives (Coreper). Lewis describes how representatives of EU member states abide by standards of appropriateness in Coreper, such as: the norm not to 'push for a vote' under conditions of qualified majority voting; obligations to practise mutual responsiveness, and to collectively legitimate arguments; as well as a sense of duty to find solutions and not obstruct the council's agenda (Lewis, 2005, p. 939). However, Lewis points out that the culture that sustains these norms in practice does not seem to trigger shifts of loyalty or transfers of allegiance in ways predicted by Haas (Chapter 3). Rather, national and European preferences seem to become increasingly intertwined.

Ana Juncos and Karolina Pomorska apply socialization theory to analyse the codes of conduct in CWGs relating to the Common Foreign and Security Policy (CFSP) before the Lisbon Treaty. According to Juncos and Pomorska, these behaviours include a sustained reflex to coordinate and build consensus; rules which diplomats representing EU member states learn as a result of their participation in the CWGs (Juncos and Pomorska, 2006). However, they find little to support the notion that normative suasion takes place. That is, they argue that codes of conduct are respected in order not to compromise actors' perceived credibility within the group, because the lack of credibility is commonly understood as something that might decrease the chances of influencing the outcome of the decision-making process. In this sense, socialization in the CWGs seems to be primarily driven by a cost-benefit analysis. Interestingly, Liesbet Hooghe, in a study of socialization processes in the European Commission, found little support for socialization within the Commission in spite of its high degree of institutionalization, significant resources and control over carrier paths. However, Hooghe notes that national and international norms often overlap: '[The] most powerful influences on pro-European support among top officials are national or subnational. National and subnational socialization can, and do, produce support for international norms' (Hooghe, 2005, p. 888).

Thus, even in the 'thick institutional environment' such as contemporary Europe there seems to be good reasons to assume that 'norms of consultations and reciprocity ... can exist at least partially independently of substantive norms and values' (Ikenberry, 2008, p. 26). Interestingly, Checkel and Peter 
Katzenstein note that European integration seems - more than 60 years after the Schuman Declaration was signed - to be 'based on a relatively thin conception of collective identity that is lacking in emotional strength' (Checkel and Katzenstein, 2009, p. 12). It is noteworthy that Lewis suggested some 15 years ago that EU enlargement might alter the conditions under which the standards of appropriateness are upheld in Coreper and that it is possible that the identity configuration of EU permreps [might] revert to more egoistic and instrumental variants [that might] over time, affect the perceived legitimacy of the EU's collective decision-making culture' (Lewis, 2005, p. 969). Considering that the increasing contestation in preparatory bodies within the CFSP (see Michalski and Danielson, 2020; Maurer and Wright, 2020; and Chapters 5 and 6 in this book) is primarily driven by an increased impact of domestic politics from some member states, this seems to have been a rather accurate prediction.

The variation in identity outcomes among national diplomats and EU officials also indicates that socialization processes should not be seen as having only two possible outcomes (internalization or no internalization), but rather as contingent on the engagement and interaction of other social mechanisms, including national/subnational socialization, previous work experiences, and the hierarchical position of one's community of practice. Although they should not be reduced to their observable outcomes, we can view such mechanisms as conditions for the specific norms and practices that arise within a community of practice regarding its purpose, procedures, and how it should manage differences and contestation. It is precisely this variation that is highlighted in the empirical chapters of this volume.

\section{Practice Approaches}

Although there is no unified theory of practice in social science, most theories of practice assume that social practices are best understood as embodied and meaningful patterns of action (see Schatzki et al., 2001; Reckwitz, 2002; Nicolini, 2013). Therefore, practice approaches differ from socialization theory in their theoretical focus. Rather than being interested in the mechanisms of how and why norms and identities are internalized, practice approaches are interested in identifying and describing the practical knowledge that guides practitioners' common sense.

Practice approaches in IR and European studies offer a range of useful insights to the study of EU foreign and security policy (see Neumann, 2002; Adler and Pouliot, 2011b; Bueger and Gadinger, 2018; Adler-Nissen, 2016; Bicchi and Bremberg, 2016). Interestingly, many of the early 'socialization studies' referred to above found little evidence of effective norm internalization but were able to describe a whole range of social practices that make EU actions in the field of foreign and security policy possible. For example, 
Rebecca Adler-Nissen suggests that 'as a result of over 50 years of painstaking work by officials from the European states, a social field has developed - an autonomous social system comprising a pattern of practices and shared meanings, where certain rules and roles result in competent action' (Adler-Nissen, 2014a, p. 4).

Several recent studies point to further analytical benefits of studying different aspects of EU foreign and security policy-making from the perspective of practice. Kathleen McNamara (2015) has shown how practices of EU foreign policy are localized in member states as a way to legitimize sensitive shifts in political authority in certain issue areas. Federica Bicchi (2011) found that the officials involved in using the COREU network display key features of a community of practice (for example, a shared repertoire of practices that negotiate meaning). Nina Græger (2016) has analysed how a shared, informal repertoire of practice has emerged in Brussels and in mission areas where both the EU and the North Atlantic Treaty Organization (NATO) operate to bypass political stalemate. Magnus Ekengren (2018) describes how EU action in foreign and security policy is largely forged by transnational diplomatic routines and crisis management procedures. Other recent contributions focus on various aspects of practice, such as diplomatic negotiations in the EU and the United Nations (UN) (Adler-Nissen and Pouliot, 2014), burden-sharing in European military operations (Mérand and Rayroux, 2016), EU counter-piracy operations (Bueger, 2016), European diplomats in the Israeli-Palestinian conflict (Bicchi, 2016), the EU and climate-related security risks (Bremberg et al., 2019), as well as Brexit and European security and defence (Svendsen, 2019).

The 'practice turn' in IR is sometimes portrayed as primarily a critique of both rationalist and constructivist theories in IR and European studies, which view representations as central to explaining actions in international politics. In this sense, many scholars drawing inspiration from practice approaches likely agree with Pouliot's (2008) argument that there is a 'representational bias' in IR. Rather than emphasizing representational knowledge and assuming that actors either strategically discern potential action outcomes to act, or reflect on the most appropriate course of action given the identity of the self and other(s), practice theorists argue that actors might also act because doing so simply appears self-evident (Pouliot, 2008). In any case, to perform actions often requires a whole range of practical skills that actors might master without necessarily being able to explain or justify. For this reason, the actions of a diplomat serving in Brussels should not necessarily be reduced to either rational calculation or conscious rule-following, as doing so would be looking at their actions only 'from above' without considering the context-specific practical logics found in their environment. Practices should be defined, according to Adler and Pouliot (2011a, p. 4), as 'socially meaningful patterns of action, which, in being performed more or less competently, simultaneously embody, 
act out, and possibly reify background knowledge and discourse in and on the material world'.

Rather than focusing on why people act the way they do, Adler and Pouliot suggest that we should place a larger focus on what people are doing and how they do it, not least because it is methodologically very difficult - if not impossible - to get inside people's minds to establish whether a norm really has been internalized, or to what extent various action options have been strategically assessed. In contrast to socialization theory, practice approaches tend to focus on background knowledge (that is, the knowledge that actors 'think from' rather than 'think about'). Background knowledge is the kind of knowledge that actors often acquire over time through lived everyday experiences, and therefore it tends to be intuitive and inarticulate. In contrast, representational knowledge is reflexive and intentional as it can be 'verbalized' and be subject to instrumental or normative reasoning (Pouliot, 2008, pp. 270-271). That is, representational knowledge is the substance of socialization and persuasion, whereas background knowledge is a prerequisite for acting in line with a certain practice.

Background knowledge is similar (albeit not entirely identical) to Pierre Bourdieu's notion of habitus: a system of 'durable, transposable dispositions' that constitute a basis for people's thoughts and actions (Bourdieu, 1990, p. 53). According to Bourdieu, a person's habitus is the result of their experiences or the 'unspoken know-how, learned in and through practice, and from which deliberation and intentional action becomes possible' (ibid., p. 53). On a societal level, such assumed knowledge is defined as the doxa: the shared self-evident 'truths' about the world that structure relations between groups and individuals. Therefore, the ability to define doxa is a form of power, which obviously is unequally distributed (Eagleton-Pierce, 2013, pp. 50-55). Similarly, Adler (2019, p. 122) understands the individual capacity to selectively retain and shape the meanings of certain practices within a group as 'epistemic practical authority'.

A related Bourdieuan concept is field: a particular social universe or 'microcosm' where individuals hold a different and unequal position (Pouliot and Mérand, 2013; Leander, 2011). For Bourdieu, positions and relations within any social field are structured by different levels of capital, such as economic, social, cultural and symbolic. Individual actors are dispositioned (but not completely determined) towards certain practices as a result of the contingent 'encounter' between their habitus and their position in the field (Pouliot and Mérand, 2013). Pouliot describes the outcome of this encounter as a 'practical sense', what Bourdieu and Wacquant describe as a 'socially constituted 'sense of the game' (as cited in Pouliot, 2010, p. 35). This practical sense forms the basis of the 'logic of practicality', that is, what actors think they can do, not what they think they should do (Pouliot, 2010, p. 35). Because 
Table 4.1 Socialization theory and Bourdieuan practice theory

\begin{tabular}{l|l|l}
\hline & Socialization theory & \multicolumn{2}{l}{ Bourdieuan practice theory } \\
\hline Cognitive status & Reflexive/explicit & Non-reflexive/tacit \\
\hline $\begin{array}{l}\text { Why do people follow rules/ } \\
\text { norms/practices? }\end{array}$ & $\begin{array}{l}\text { Because they want to maximize their } \\
\text { preferences, fit in or act in the way } \\
\text { that is perceived as legitimate }\end{array}$ & $\begin{array}{l}\text { Because it feels like the self-evident } \\
\text { thing to do }\end{array}$ \\
\hline $\begin{array}{l}\text { How is rule-following } \\
\text { performed? }\end{array}$ & $\begin{array}{l}\text { Demonstrating internalization (about } \\
\text { what one should do) }\end{array}$ & $\begin{array}{l}\text { Demonstrating competence (about } \\
\text { what one can do) }\end{array}$ \\
\hline $\begin{array}{l}\text { How do people learn what } \\
\text { to do? }\end{array}$ & $\begin{array}{l}\text { Calculation, role-playing and } \\
\text { reasoning }\end{array}$ & $\begin{array}{l}\text { Through the contingent encounter } \\
\text { between dispositions and positions }\end{array}$ \\
\hline $\begin{array}{l}\text { Type of knowledge that } \\
\text { drives action }\end{array}$ & $\begin{array}{l}\text { Representational knowledge (of/ } \\
\text { about something) }\end{array}$ & $\begin{array}{l}\text { Background knowledge (how to do } \\
\text { something) }\end{array}$ \\
\hline
\end{tabular}

the logic of practicality strongly resembles action based on the doxa, it can help to explain when and why actors act appropriately or act on the basis of instrumental rationality. This is because the intersection between the habitus and one's position in the field can give rise to either a logic of appropriateness or a logic of consequence, which makes the performance of any action in line with the established practice (irrespective of it being an 'appropriate' action or an action based on instrumental calculation) of the self-evident thing to do in a specific situation (Pouliot and Mérand, 2013, p. 31). However, in Bourdieu's theory of practice, social fields are conceived of as inherently hierarchical and therefore are not neutral or fair in the sense that all members of a field are equally involved in shaping the doxa. Various forms of social inequalities are assumed to be upheld even by those who are dominated by them, often as a result of rationalizing the status quo. In other words, structurally disadvantaged actors are 'cognitively complicit in their own domination' (Pouliot and Merand, 2013, p. 37). Depending on an actor's position in a social field, we should expect individual dispositions to have either a greater or a weaker impact on intersubjective dispositions, which in turn determine shared practices (Pouliot, 2010, pp. 35-36).

To visualize the differences between socialization theory and Bourdieuan practice theory, we have summarized their primary assumptions in Table 4.1. As mentioned above, neither of these perspectives are, in our view, sufficient for understanding how practices are diffused among the practitioners of EU foreign and security policy. As we show in the following empirical chapters, the practitioners of the CFSP are seemingly far more conscious of their practices than Bourdieuan practice theory would assume, especially as a result of the increased degree of contestations from member states, a condition that forces individual diplomats to create new practices or actively argue to uphold existing practices to manage such contestations. At the same time, the practi- 
tioners of the CFSP do not always act on the basis of norms or instrumental calculation; that is, they also act on the basis of a practical sense, or 'what we do here' in a given group or community. Therefore, we believe a more inclusive conception of practices should be used to understand the diffusion of practices in the context of EU foreign and security policy. This conception is outlined in the following section.

\section{SOCIAL PRACTICE AS MEANINGFUL ACTION}

As previously described, there is no unified theory of practice in social science and it would therefore be unfortunate to equate the 'practice turn' in IR to different interpretations of Bourdieu's work. The works of scholars such as Michael Foucault, Etienne Wenger, Bruno Latour, Theodore Schatzki, Ann Swidler and Luc Boltanski have also been used to theorize practices in IR (e.g., Bueger and Gadinger, 2018). Advancing the notion that practice approaches in IR are pluralistic endeavours, Sylvia Lechner and Marvyn Frost's work, which partly draws on Ludwig Wittgenstein's notion of practice, and Adler's work, which builds on Wenger's concept of communities of practice, are especially helpful as a basis for our analytical framework. In their definition of practices, Lechner and Frost assume that practices cannot be understood and explained without trying to recapitulate the internal meanings of the practice in question (Lechner and Frost, 2018, p. 83ff). On this basis, they criticize attempts to reduce practices to 'competent performances' which, they argue, amount to a view of practices as simple actions whose successful performances do not require an understanding of the 'complex social facts about the practice as a whole' (ibid., p. 50). ${ }^{2}$ Examples of such actions include walking, swimming, riding a bike, and kicking a ball. These actions are independent of what we know about the overarching practice in which they may take place. However, learning the rules of a practice - and following those rules - always depends on the context in which they are acted out.

\footnotetext{
2 However, it should be said that Adler and Pouliot hint in this direction, as they acknowledge that actions should be understood as being specific and located in time, whereas practices are better understood as general classes of action not necessarily confined to any delimited act (Adler and Pouliot, 2011a). Pouliot suggests that practices are mostly learned through practical experience (Pouliot, 2008, p. 272), whereas Lechner and Frost contend that any action that is more complex (that is, defined by rules) than simple action cannot be learned without a description of its rules. In other words, the novice must first be given some rules to adhere to before being able to act within the framework of a social practice, even if the meaning of those rules is later learned through the act of rule-following (Lechner and Frost, 2020, p. 221).
} 
In this view, a practice-dependent action requires that the practitioner is to some degree conscious of the rules constraining the practice before acting in line with them, as it is through understanding the context of the practice in question that its rules can be learned. For this reason, Lechner and Frost argue that we should adopt an internalist view of practices; that is, the meanings of practice-dependent action can only be understood in the language of the practitioners. Adler suggests something quite similar, as he emphasises that practices are performed in communities of practice in which individuals must learn the collective's meanings and identities:

individuals acquire their knowledge when they learn to participate in the knowledge of others. From a collective perspective, however, learning means the evolution of background knowledge or the substitution of one set of conceptual categories that people use to give meaning to reality with another such set. From this perspective, learning requires not only the internalization of new knowledge by individuals but also the institutionalization of dispositions and expectations in and by means of practice. (Adler, 2008, p. 201; see also Adler, 2019, p. 111)

The interaction between practitioners within a community of practice 'creates the social fabric of learning', which upholds the community's shared definition of what should be regarded as competent performance, as well as the common identity which this form of competence constitutes (Adler, 2019, pp. 112-113). Therefore, the negotiation of the shared definition of competence shapes and sustains the community's identity. For this reason, Adler argues that contestation, understood as the negotiation of the group's definition of competent performance and practices, should be viewed as a constitutive element of learning within communities of practice:

One should take contestation as one of the most important attributes of communities of practice. Contestation is necessary for learning in communities of practice. It is a process by which practitioners dynamically define their practice, adapt to environmental challenges, and adopt a common identity. Learning and contestation determine both the shared meanings with which practices are bound and the selective retention processes that depend partly on 'who gets what, whom, and how' (Lasswell, 1936) in and between communities of practice. (Adler, 2019, p. 114)

To understand how a community of practice evolves, as well as the practices that arise from the interaction within a specific community, we must also understand the processes of contestation within the community. This includes understanding variation in terms of the members' epistemic practical authority in shaping the outcome of such contestation, as well as practices regarding how contestation within the community should be handled. Given the fact that contestation management should likely be seen as complex practice-dependent action (and not simple action), how a community deals with contestation 
should also be understood through the language of its practitioners. Using this understanding as a point of departure, many of the empirical chapters in this volume examine how diplomats and officials in EU foreign and security policy manage contestations. However, simply because the practices of contestation management can vary across institutional settings, this does not mean that they necessarily will. For example, when comparing how diplomats from EU member states coordinate among themselves and with the EU delegations as well as manage disagreements on-site in Washington and Beijing, we found that the ways in which consensus is forged and contestation is managed is quite similar: both groups place a high value on friendly relations, avoiding surprises, and possessing a relatively high degree of subject knowledge. In addition, if one of the members of the two groups opposes the group's majority position, they are expected to provide a clear and convincing reason for why they must break ranks. A number of similar practices were mentioned throughout our interviews with practitioners in Brussels, Washington and Beijing (Chapters 6 and 8).

In this sense, both Adler's view of learning in communities of practice, and Lechner and Frost's internalist view on practices, appear quite different from Pouliot's understanding of the logic of practicality, which posits that background knowledge is non-reflexive and unconsciously known, to the point that practitioners would not necessarily be able to explain the rules that guide their actions. This condition forces observers to guess what the practice in question is about. This view of social practices seems to require an externalist standpoint (that is, the practice can be explained independently of what practitioners think). By viewing practices from an externalist point of view, Lechner and Frost argue that we continuously run the risk of explaining a different practice than the one we are observing. In other words, if we do not seek to determine what a practice is, based on its intrinsic meanings as understood by the practitioners, the meaningfulness of a practice is lost to outsiders. For example, the practice of learning from CSDP operations and mission might differ quite significantly in terms of what practitioners in different EEAS units are doing on a daily basis, although they can still be said to be part of the same community of practice of civil and military crisis management in the EU. This situation might shape what lessons are being diffused to national capitals and representatives in Brussels (Chapters 7 and 9).

In essence, Adler as well as Lechner and Frost argue that practice-dependent action is largely bound in the constitutive rules of that practice. For example, to advance a country's interests in PSC negotiations on sanctions, or implement a project to assess the humanitarian consequences of climate change in the Sahel, EU member state representatives or EEAS officials must first learn the rules that constitute actions as a part of the practice of EU negotiations or project management in EU foreign and security policy. In this sense, the 
background knowledge or logic of practicality that informs how one should act cannot be seen mainly as 'unconsciously held knowledge', since the rules underpinning a practice are not learned unconsciously (cf. Pouliot, 2010, p. 12; Pouliot, 2008, p. 272). For example, a diplomat does not learn how to 'analyse, describe or judge in an unconscious manner, even though many diplomatic skills may subsequently be deployed in a tacit (unreflexive) manner' (Lechner and Frost, 2018, p. 83). In a nutshell, practices are consciously learned, but often unconsciously used. We argue, therefore, that the logic of practicality is useful in explaining and understanding why actors unconsciously act in line with established practices at different times. For example, newcomers might try their best to mimic what is perceived to be the ways of doing things in a community of practice, and more senior members might tacitly perform actions well in line with the practices of the community. But acquiring the practical understandings that embody background knowledge in concrete settings such as the PSC, EU delegations and EEAS requires the intertwining of reflexivity and non-reflexivity.

\section{OUTLINE OF THE ANALYTICAL FRAMEWORK}

Although the logic of practicality is often taken for granted within theoretical accounts of diplomacy, we argue that previous research has neglected the ways in which this logic comes into play. Here, we argue that the logic of practicality - that is, the conditions under which agents act on the basis of tacit background knowledge - can be theorized using the socialization mechanisms presented above. That is, our analytical framework should be understood more as an eclectic approach than as a tool for testing specific hypotheses.

Because our analytical framework primarily analyses how individual diplomats and officials are socialized into communities of practice, it is not applicable for understanding the macro level of learning and contestation, both aspects important for the production and retention of practices. However, we have chosen to limit the analytical framework to another level of the diffusion of practices. In addition, the framework does not seek to assess norm internalization, but rather to understand how practices diffuse and evolve in EU foreign and security policy as a result of everyday interactions involving learning and contestation. Thus, our analytical framework focuses on individuals, as we assume that scholars can approach the diffusion and evolution of practices in EU foreign and security policy by way of analysing practitioners' accounts of their everyday interactions, which is also why the empirical chapters largely rely on interview data.

This analytical framework combines Pouliot's logic of practicality, Lechner and Frost's view of conscious practical learning, and Adler's concept of community of practice, with the previously described socialization mechanisms. 
We do not assume that our framework precisely captures all aspects of how practices are learned in any specific working group, committee, mission or other diplomatic settings in EU foreign and security policy. Nevertheless, we argue that the framework is useful for understanding how learning and contestation may be affected by different conditions, most notably the time spent in a formal group or institution, as well as for illustrating the role of conscious reflection of the constitutive rules of the group's practices in such processes.

To understand how socialization mechanisms affect the way agents learn to tacitly perform a group's practices, we start with the process of how a novice is inducted into a community of practice. Johnston (2008) argues that novices in an international institution are often initially socialized through the mechanism of mimicking: a process where novices unreflectively imitate the actions of the rest of the group because mimicking is the safest way to behave in an unknown social environment. ${ }^{3}$ In other words, this type of action can be understood as a simple action; it is judged by the established members of the community on the basis of whether or not it is competently performed, even though the novice might not yet have learned the constitutive rules of the practice. However, it is likely that the novice will soon want to understand why the members of a community of practice are acting as they do, and as such, the degree of reflexivity over the rules that constitute the practice will increase. This process will likely be amplified by efforts to persuade the novice to accept the constitutive rules of the community's practices. Simply put, the more effort that goes into 'verbalizing' a practice, the more likely it is that that practitioners will become conscious of the practice.

It is important to acknowledge that most of the cases of socialization that we are interested in as IR scholars, and particularly as researchers studying EU foreign and security policy, involve studying the emergent social dynamics in international institutions where practitioners with varying degrees of previous training and experience interact. These previous experiences are also likely to affect the practitioners' assumptions about who needs to learn what. Because diplomats and other EU officials representing an EU member state in the PSC or heading a unit in the EEAS most likely have experience with other posts, it is likely that these officials' sense of seniority will affect how they interact with their subordinates as well as their peers. Therefore, the level of seniority will also likely play a large part in determining whether a novice will reflect on the practices related to a particular group and institution in the EU, or whether they will simply be seen as extensions of their previous commonsense understanding of how the EU foreign and security policy works.

See Autesserre (2014, pp. 38-39) for an example of how 'ways of understanding and acting' are diffused. 
Nonetheless, when novices reflect about the practice in question, the less they will act on the basis of a logic of practicality. Instead, they will likely start to act on the basis of representational logics of action, such as the logic of appropriateness or consequences (March and Olsen, 1998). Over time, novices will gain a sufficient amount of understanding of the constitutive rules of the community's practices such that they will either consciously contest them or accept them; essentially, what Hirschman (1970) calls voice or loyalty. ${ }^{4}$ Gaining this understanding can take a significant amount of time (cf. Adler-Nissen, 2014a), ${ }^{5}$ but the learning process will eventually lead to either a redefinition of the practice - if the novice has sufficient epistemic practical authority to induce change - or maintaining the status quo through sustained compliance. By status quo, we refer to the practice maintaining its meaning within the community. Compliance may in turn be the result of strategic calculation (instrumentality), social influence (wanting to fit in and/or avoid opprobrium) or successful persuasion. Irrespective of which mechanism takes hold, they all imply that the novice actively reflects on the utility or legitimacy of the constitutive rules of the community's practices. At this stage of the process of practical learning, the degree of consciousness about the constitutive rules of the group's practices is high.

After novices learn the practices of a community, they can follow one of three routes: habituation of the constitutive rules of the practice(s) as they become increasingly taken for granted; contestation endures as the constitutive rules are rejected; or new practices are developed as a result of creative variation. Sustained contestation should be conceptualized as a possible outcome of a group's inability to adapt a practice that is perceived as too salient for one or more actors to simply ignore. Similarly, creative variation and the development of new practices should be understood as a potential consequence of reflexive contestation as well as a pragmatic solution to diverging perceptions of the value of the group's existing practices (Adler, 2019, pp. 223-224). However, if an existing practice is accepted and habituated, the novice will gradually cease to reflect about its constitutive rules, and the perceived prescriptiveness of the group's practice will eventually fade away, marking the novice's transition into the group as an experienced member. ${ }^{6}$ At this point, the group members will simply know what to do because it feels self-evident.

4 As Hirschman noted, the possibility of 'exit' exists as well. However, to simplify the framework that we develop here, we avoid theorizing the conditions under which 'exit' would be more likely than one of the other two options.

5 For example, Pouliot (2016) observes that it can take at least a year for diplomats in NATO and the UN to learn the 'feel for the game'.

6 See Hopf (2010) for a similar argument on how habits can establish and reproduce social order. 
Here, the logic of practicality yet again becomes a useful concept, as at this stage we assume that the degree of reflexivity and consciousness about the group's practice(s) are at their lowest point, which presumes that both the newest members and established members of the group tacitly act on their shared practical understandings.

In sum, we argue that the logic of practicality is most common among two types of actors in international institutions: novices and established members. Novices will likely mimic other actors despite not actively reflecting on the practices in question, but unreflective mimicking will eventually give way to a more reflective assessment of the meaning of the rules being mimicked. To become a full member of the group, the novice must not only mimic, but also learn the constitutive rules of the community's practices. We argue that this transition primarily happens through the socialization mechanisms of persuasion and social influence, which can be understood as attempts of social reproduction. That is, the established members will likely uphold the community's practices and do so by using their epistemic practical authority (Adler, 2019). The more intense this contestation becomes, the more conscious the actors will be about the practices in question. Over time, the novices and the established actors may find something of a stable equilibrium in which either the existing practices or the new, negotiated practices become habitual, and are eventually fully internalized as beliefs about 'what works' (Adler, 2019, p. 244). Pouliot's rendition of the logic of practicality helps to explain why actors act the way they do, both during a novice's introduction into a community of practice as well as when a significant amount of time has passed and the constitutive rules of the community's practices have become internalized. However, in between these stages, we should be open to the possibility that practices can change as a result of reflective contestation, as well as the possibility that this contestation is maintained or intensified over time due (see Hopf, 2018).

\section{STUDYING THE EVERYDAY MAKING OF EU FOREIGN AND SECURITY POLICY}

The above analytical framework informs the empirical analyses presented in this book. Specifically, the analyses highlight four dimensions of how the everyday making of EU foreign and security policy works in communities of practice: group-level interaction, learning, contestation, and autonomy from the domestic setting. According to the framework, these dimensions are likely to interact in and affect the process of diffusing practices in a given community.

We have already suggested that communities of practice in EU foreign and security policy might coincide with formal groups and institutions within the EU, but they cannot be reduced to them. Simply put, a CWG is not in itself a community of practice, but should rather be understood as a social venue that 
regularly brings a specific set of practitioners together. These communities of practice include diplomats of the CWG who interact frequently, as well as representatives and EU officials who, although not formal members of the $\mathrm{CWG}$, work closely with CWG members to produce EU foreign and security policy vis-à-vis a particular issue or country. Therefore, a community of practice might also include national diplomats who previously were members of the CWG but are in new positions in Brussels, New York, Geneva, or elsewhere. In addition, the social dynamics among the formal members of the CWG can be influenced by different, and at times conflicting, practical understandings and ways of doing things that stem from different communities of practice, superseding the formal boundaries of the particular CWG.

We suggest that time spent in any formal groups or institutions in the EU influences reflexivity and practical learning, but time alone cannot fully account for the social dynamics within communities of practice. Indeed, these dynamics need to be explored empirically and as closely as possible to the practitioners' lived experiences and practical understandings. However, no observation of practices is possible without some theoretically informed notion of what aspects might be relevant to observe, a conception that needs to be informed by the research task at hand. Therefore, to study the above dimensions of how EU foreign and security policy are produced, we have used the following sets of questions to guide our interviews and other means of data collection:

- Group-level interaction: How do representatives/participants interact on a regular basis? What practices are important for carrying out the task of the organ/aspect according to the representatives/participants and which role do they play for this organ/group/aspect of EU foreign policy-making?

- Learning: How are skills that are important to the function of group/organ/ aspect learned? Which procedural and constitutive norms are regarded as important by the representatives/participants? What formal and informal practices guide the working environment/group dynamics? What characterizes successful and competent actions?

- Contestation: What is the role of consensus and how is it reached? What role does the policy/consensus play in Brussels with respect to the work of this organ/aspect of EU foreign policy-making? To what degree is dissent tolerated and how does the group overcome dissent/lack of consensus?

- Autonomy from domestic politics: What is the impact of national foreign policy/national governments on the work of the organ/aspect of EU foreign policy-making? Do the representatives/participants get instructions from their Ministry of Foreign Affairs (MFA)? Are they empowered to interpret or go beyond these instructions? What characterizes the communication with headquarters: unilateral/bidirectional information and input or 
something else? Do member states maintain different kinds of interaction between representatives in and beyond Brussels, and what impact does this have on the everyday making of EU foreign and security policy?

Beyond the fact that these questions allow us to probe potential differences between the groups and institutions of EU foreign and security policy, the overarching themes can also be regarded as both mechanisms and conditions for different outcomes in terms of the practices that develop within a community of practice. As previously mentioned, depending on how these mechanisms interact, the community of practice will likely have a specific way of managing contestation; one that differs from other similar, although different, communities. However, it is probable that similarities will also arise as a result of practical knowledge shared not only among the members of individual communities of practice, but also among the practitioners of the CFSP as a whole. In the following empirical chapters, we identify and analyse these differences and similarities to map the field of knowledge that constitutes and produces EU foreign and security policy, and to better understand how group-level differences can account for the production and evolution of different practices. 